\title{
Computational fluid dynamics analysis of a ship's side launching in restricted waters
}

\author{
A. Fitriadhy* and A.M.A. Malek \\ Program of Maritime Technology, School of Ocean Engineering, \\ Universiti Malaysia Terengganu, Malaysia. \\ *Email: naoe.afit@gmail.com \\ Phone:+6096683856; Fax: +6096683193
}

\begin{abstract}
In the presence of a highly complex phenomenon during a ship's side launching, a more reliable approach to predict the launching performance is thus required. To achieve the objective, a Computational Fluid Dynamic (CFD) simulation is proposed to obtain more accurate results. Several parameters such as various angles and lengths of the sliding platforms have been taken into account in the simulation which was aimed at providing an insight into their dependencies on the ship's side launching performance, mainly quantified as the ship's tipping time. Computational simulations revealed that an increase of the platform's angle from $3^{\circ}$ to $4^{\circ}$ had led to an increase in the launching speed percentage by $17.9 \%$, which consequently resulted in faster tipping time of about $21.4 \%$ compared to the increase of the platform's angle from $4^{\circ}$ to $5^{\circ}$. However, opposite results were shown as the tipping time became slower by $22.2 \%$ and $9.1 \%$ due to the increase of $\mathrm{d} / \mathrm{L}$ ratios from 0.13 to 0.18 and from 0.18 to 0.23 , respectively. It is generally concluded that increasing the platform's angle and decreasing the $\mathrm{d} / \mathrm{L}$ ratios can result in faster tipping time. With regards to the CFD results, these preliminary findings can act as best practice guidelines, especially for naval architect engineers.
\end{abstract}

Keywords: Side launching; platform angle; platform distance; tipping time.

\section{INTRODUCTION}

A ship's launching is one of the important processes representing the beginning of a ship's life in water. The launching operation is a vital process since the launching stage is a time consuming process, as well as involves high costs [1]. A successful launching floats the ship safely on the water in an equilibrium condition. Basically, there are two kinds of ship launching which are commonly practised; the longitudinal or the side ship launching [2] [3]. In restricted waters such canals and rivers which are associated with less longitudinal strength for the ship [4], the side launching is normally chosen instead of the longitudinal method. The ship side launching is a hectic and dynamic process as it also involves sixdegrees-of-freedom of a ship's motion responses, as well as the process of putting the ship into the water. Ye presented a theoretical solution in the form of a numerical method in which the motion of a side launching ship is set to three degrees-of-freedoms [5]. The ship side launching method is vulnerable to some serious risks as reported by Hak [6], such as structural damages or capsizing due to abrupt heeling once the ship falls into the water. By applying the gravitational concept, a ship commences to slide down the platform and launches into water. When ship falls into the water, she returns to an upright 
position after experiencing instability which is caused predominantly by her rolling motions. Conceptually, the ship side launching method has two different launching ways; the first way is by launching the ship by sliding it into the water, while the second method is by sliding the ship on a platform so that it inherently falls into the water [7]. To ensure a safe launching process, therefore, a comprehensive study on the ship side launching method is necessary to avoid the aforementioned serious risks. In this paper, the authors propose a ship side launching analysis by applying the second method using the Computational Fluid Dynamic (CFD) approach. The commercial CFD software used is Flow-3D Version 10.1. Several parameters such as various inclination angles from $3^{\circ}$ up to $5^{\circ}$ and lengths of sliding platforms with respect to the ship's length $(\mathrm{d} / \mathrm{L})$ from 0.13 up to 0.23 were taken into consideration to identify the ship's launching performance. Some probes were placed in the computational domain to measure the maximum free surface water elevation (water splashing) as the ship falls into the water. The parametric studies put forward here are aimed at providing an insight into their dependencies on the tipping time during launching. In addition, the maximum value of Under Keel Clearance (UKC) and the characteristics of the ship's motions responses i.e., roll and heave motions are presented in the simulation results. With regards to the CFD results, this work will provide a prominent insight into a more realistic model of the ship side launching simulation compared to the empirical approach. Due to the insufficient number of published manuscripts discussing the ship side launching simulation, we do hope that the current paper would become a valuable literature reference in the future.

\section{METHODS AND MATERIALS}

\section{Governing Equations}

\section{Continuity and momentum equation}

The continuity and momentum equations for a moving object and the relative transport equation for the VOF function are

$$
\begin{aligned}
& \frac{V_{f}}{\rho} \frac{\partial \rho}{\partial t}+\frac{1}{\rho} \nabla \cdot\left(\rho \vec{u} A_{f}\right)=-\frac{\partial V_{f}}{\partial t} \\
& \frac{\partial \vec{u}}{\partial t}+\frac{1}{V_{f}}\left(\vec{u} A_{f} \cdot \nabla \vec{u}\right)=-\frac{1}{\rho}\left[\nabla_{\rho}+\nabla \cdot\left(\tau A_{f}\right)\right]+\vec{G} \\
& \frac{\partial F}{\partial t}+\frac{1}{V_{f}} \nabla \cdot\left(F \vec{u} A_{f}\right)=-\frac{F}{V_{f}} \frac{\partial V_{f}}{\partial t}
\end{aligned}
$$

where $\rho$ is the density of the fluid, $\vec{u}$ is the fluid velocity, $V_{f}$ is the volume fraction, $A_{f}$ is the area fraction, $p$ is the pressure, $\tau$ is the viscous stress tensor, $G$ denotes gravity and $F$ is the fluid fraction.

In the case of a coupled GMO's motion, Eqs.(1) and (2) are solved at each timestep, the location of all moving objects is recorded, and the area and volume fractions updated using the FAVOR technique. Equation (3) is solved using the source term $\left(-\frac{\partial V_{f}}{\partial t}\right)$ on the right-hand side, which is computed as

$$
-\frac{\partial V_{f}}{\partial t}=\vec{U}_{o b j} \vec{n} S_{o b j} / V_{c e l l}
$$

where $S_{o b j}$ is the surface area, $\vec{n}$ is the surface normal vector, $\vec{U}_{o b j}$ is the velocity of the moving object at a mesh cell, and $V_{\text {cell }}$ is the total volume of the cell [8]. 


\section{Turbulence Model}

The RNG turbulence model was used for the simulation of the exchange flow between open water and floating objects since it accounts for a low Reynolds number effects [9],[10],[11]. Applying the double averaging strategy to the transport equations for TKE and its dissipation rate produces the turbulence model for the flow. The resulting equations are:

$$
\begin{aligned}
& \frac{\delta \mathrm{k}}{\delta \mathrm{t}}+\mathrm{U}_{\mathrm{j}} \frac{\delta \mathrm{k}}{\delta \mathrm{x}_{\mathrm{j}}}=\frac{\delta}{\delta \mathrm{x}_{\mathrm{j}}}\left[\left(\mathrm{v}+\frac{\mathrm{v}_{\mathrm{t}}}{\sigma_{\mathrm{k}}}\right) \frac{\delta \mathrm{k}}{\delta \mathrm{x}_{\mathrm{j}}}\right]+\mathrm{P}_{\mathrm{k}}+\mathrm{B}_{\mathrm{k}}+\mathrm{W}_{\mathrm{k}}-\varepsilon \\
& \frac{\delta \varepsilon}{\delta \mathrm{t}}+\mathrm{U}_{\mathrm{j}} \frac{\delta \varepsilon}{\delta \mathrm{x}_{\mathrm{j}}}=\frac{\delta}{\delta \mathrm{x}_{\mathrm{j}}}\left[\left(\mathrm{v}+\frac{\mathrm{v}_{\mathrm{t}}}{\sigma_{\varepsilon}}\right) \frac{\delta \varepsilon}{\delta \mathrm{x}_{\mathrm{j}}}\right]+\mathrm{C}_{1 \varepsilon} \frac{\varepsilon}{\mathrm{k}}\left(\mathrm{P}_{\mathrm{k}}+\mathrm{B}_{\mathrm{k}}\right)\left(1+\mathrm{C}_{3 \varepsilon} \mathrm{R}_{\mathrm{f}}\right)+\mathrm{W}_{\varepsilon}-\mathrm{C}_{2 \varepsilon}^{*} \frac{\varepsilon^{2}}{\mathrm{k}} \\
& \mathrm{P}_{\mathrm{k}}=\mathrm{v}_{\mathrm{t}} \mathrm{S}^{2}=\mathrm{v}_{\mathrm{t}}\left(\frac{\delta \mathrm{U}_{\mathrm{i}}}{\delta \mathrm{x}_{\mathrm{j}}}+\frac{\delta \mathrm{U}_{\mathrm{j}}}{\delta \mathrm{x}_{\mathrm{i}}}\right) \frac{\delta \mathrm{U}_{\mathrm{i}}}{\delta \mathrm{x}_{\mathrm{j}}} \\
& \mathrm{B}_{\mathrm{k}}=\beta \mathrm{g}_{\mathrm{i}} \frac{\mathrm{v}_{\mathrm{t}}}{\sigma_{\mathrm{s}}} \frac{\delta \mathrm{s}}{\delta \mathrm{x}_{\mathrm{i}}}
\end{aligned}
$$

where $\mathrm{P}_{\mathrm{k}}$ is the shear production term of TKE, $S=\sqrt{2 S_{i j} S_{j i}}$ is the modulus of the mean rate of strain tensor, $S_{i j}=\frac{1}{2}\left(\frac{\delta U_{i}}{\delta x_{j}}+\frac{\delta U_{j}}{\delta x_{i}}\right), B_{k}$ is the buoyant production term of TKE, $W_{k}$ is the wake production tern of TKE, $W_{\varepsilon}$ is the wake production term in $\varepsilon, \sigma_{k}, \sigma_{\varepsilon}$ are the turbulent Prandtl numbers for $k$ and $\varepsilon$, and $C_{i \varepsilon}, C_{3 \varepsilon}$ and $C_{2 \varepsilon}^{*}$ are model coefficients.

\section{Body motion equations}

According to kinematics, any motion of a rigid body can be partitioned into translational motion and rotational motion. The velocity of any point of a rigid body is equal to the velocity of an arbitrary selected base point on the object, plus the velocity due to the rotation of the object about that base point. For a 6-DOF motion, the GMO model selects the object's mass centre $\mathrm{G}$ as the base point. The equations of motion governing the two separate motions for a 6-DOF motion are:

$$
\begin{aligned}
F & =m \frac{d V_{g}}{d t} \\
T_{G} & =[J] \cdot \frac{D \omega}{d t}+\omega *([J] * \omega)
\end{aligned}
$$

The explicit GMO method solves equations (1) and (2) for mass centre velocity and rotational velocity at the current time step $(n+1)$ using the hydraulic force of the previous time step (n). The discretized equations for Eqs.(10) and (11) [8], are:

$$
\begin{aligned}
& F_{h}^{n}+\sum F=m\left(\frac{V_{G}^{n+1}-V_{G}^{n}}{\Delta t}\right) \\
& T_{h}^{n}+\sum T=[J] \cdot\left(\frac{\omega^{n+1}-\omega^{n}}{\Delta t}\right)+\omega^{n} *\left([J] \cdot \omega^{n}\right)
\end{aligned}
$$

The implicit GMO method proposed in this work solves Eqs. (10) and (11) implicitly using the following numerical scheme [8]:

$$
\begin{aligned}
& F_{h}^{n}+\sum F=m\left(\frac{V_{G}^{n+1}-V_{G}^{n}}{\Delta t}\right) \\
& T_{h}^{n}+\sum T=[J] \cdot\left(\frac{\omega^{n+1}-\omega^{n}}{\Delta t}\right)+\omega^{n} *\left([J] \cdot \omega^{n}\right)
\end{aligned}
$$


where the hydraulic force and torque at the current time step $(n+1)$ are used. Unlike the explicit GMO method which solves object and fluid motions separately, the implicit GMO method solves them together through iterations.

\section{Simulation Conditions}

\section{Ship Particulars}

In the simulation, the principal dimensions of a tanker ship model are presented in Table 1 and its body plan is clearly shown in Figure 1.

Table 1. Principle dimensions of ship model.

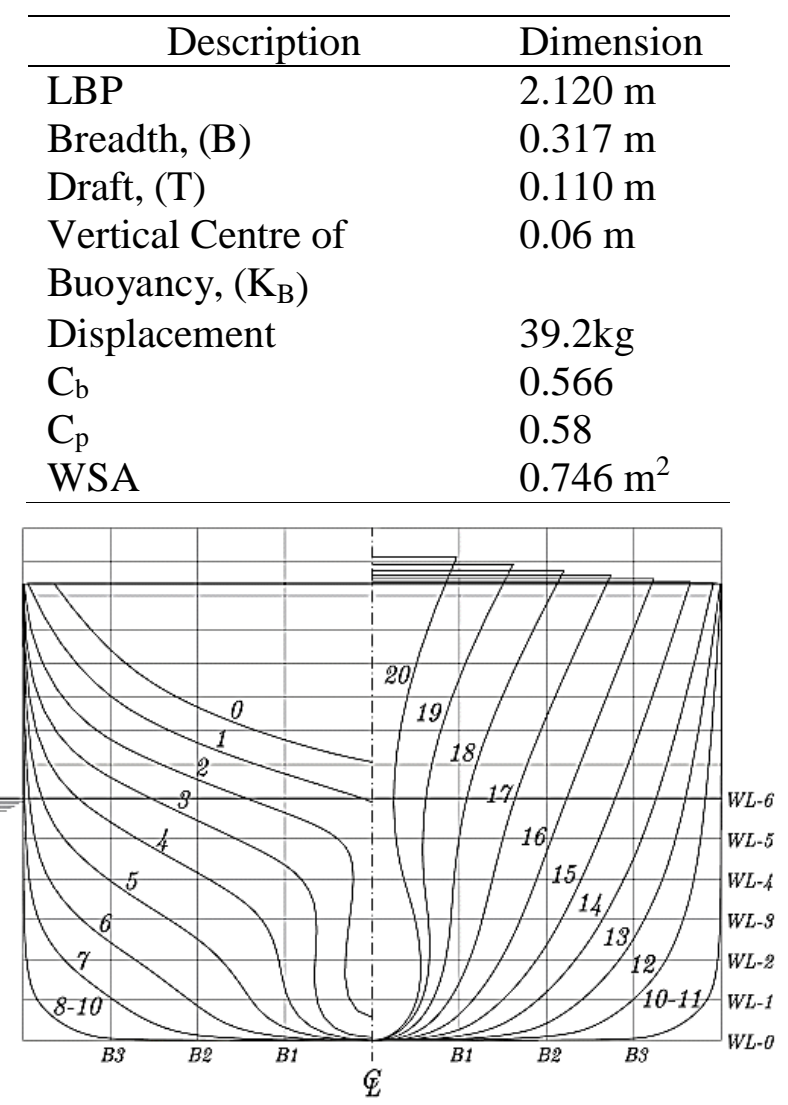

\section{Simulation Parameter}

Figure 1. Body plan

Referring to Figure 2, the ship side launching model into a pool was modelled at various angles within the range of $3^{\circ}$ up to $5^{\circ}$ (Table 2). In addition, three different length ratios of the sliding platform with respect to the ship's length $(\mathrm{d} / \mathrm{L})$ i.e., the $\mathrm{d} / \mathrm{L}=0.13$ up to 0.23 used are presented in Table 3. In this simulation, the water-depth and breadth of the pool were $0.56 \mathrm{~m}$ and $1.0 \mathrm{~m}$, respectively.

Table 2. Side launching parameters for various platform angles

\begin{tabular}{cc}
\hline $\begin{array}{c}\text { Sliding platform } \\
\text { angle, }\left({ }^{\circ}\right)\end{array}$ & $\begin{array}{c}\text { Length ratio of } \\
\text { sliding platform, }(\mathrm{d} / \mathrm{L})\end{array}$ \\
\hline 3 & 0.18 \\
4 & \\
5 & \\
\hline
\end{tabular}




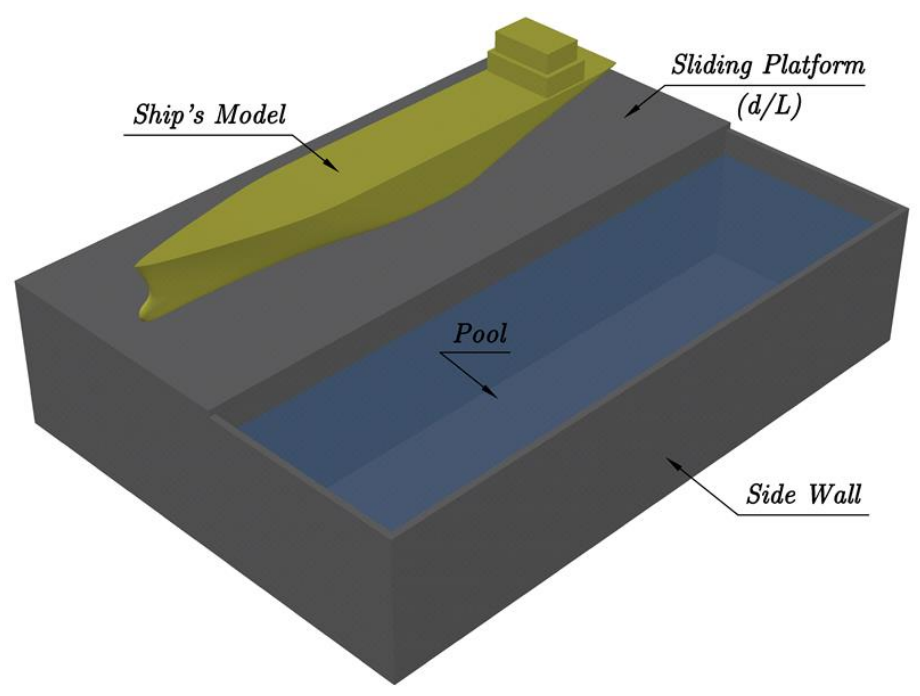

Figure 2. CFD modelling of a ship's side launching into a pool.

Table 3. Side launching parameters for various platform distances.

\begin{tabular}{cc}
\hline $\begin{array}{c}\text { Sliding platform } \\
\text { angle },\left({ }^{\circ}\right)\end{array}$ & $\begin{array}{c}\text { Length ratio of sliding } \\
\text { platform, }(\mathrm{d} / \mathrm{L})\end{array}$ \\
\hline \multirow{4}{*}{4} & 0.13 \\
& 0.18 \\
& 0.23 \\
\hline
\end{tabular}

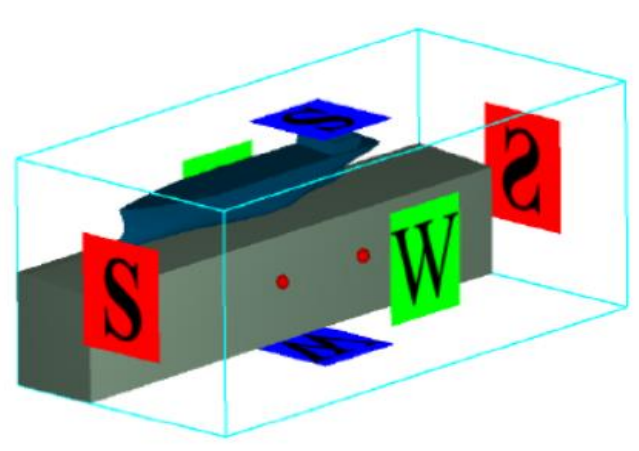

(a) Boundary setting conditions

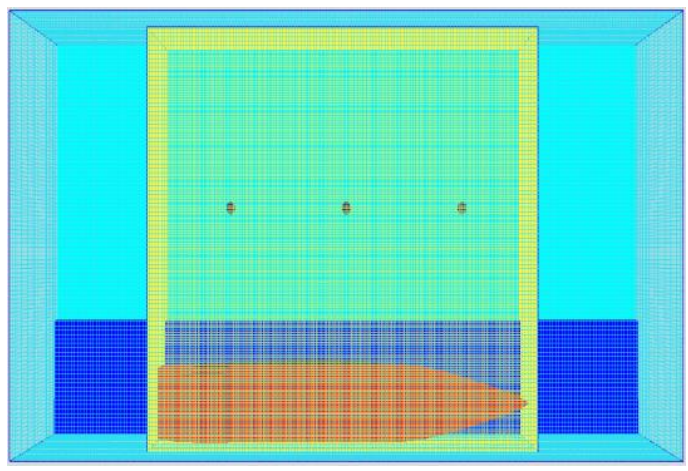

(b) Gridlines (meshing) associated with probes

Figure 3. CFD simulation conditions.

Referring to Figure 3, the computational domain of the boundary conditions for the ship's side launching simulation is displayed, where the side of the boundary is assigned as the wall type. In this mode, wall reflection is taken into account, as well as when the ship comes into water. Detailed boundary conditions are presented in Table 4. Correspondingly, grid refinement (nested mesh) has been added to provide better accuracy of the simulation results $[12,13]$. To measure the maximum water elevation (splashing) at the wall of the pool, several probes (red dots) were placed accordingly. Renormalized group (RNG) is selected because the dynamically computed maximum 
turbulent mixing length relies on an algorithm developed for a single-phase flow. Furthermore, the method is the most accurate and robust model available in the software that could simulate real-world problems [8].

Table 4. Boundary conditions.

\begin{tabular}{ll}
\hline \multicolumn{1}{c}{ Boundary } & Type \\
\hline $\mathrm{X}_{\min }($ Back) & Symmetry \\
$\mathrm{X}_{\max }$ (Front) & Symmetry \\
$\mathrm{Y}_{\min }$ (Side) & Symmetry \\
$\mathrm{Y}_{\max }$ (Side) & Wall \\
$Z_{\min }$ (Bottom) & Wall \\
$Z_{\max }$ (Top) & Symmetry \\
\hline
\end{tabular}

\section{Mesh Independent Study}

A mesh independent study is necessary to identify the adequate number of meshes in order to ensure the accuracy of computation results. Table 5 shows the result of the mesh independent study. A total number of 5,005,347 of cells in case $\mathrm{C}$ was selected from all cases as it has the most reasonable accuracy of CFD solutions associated with less computational time. Table 5 shows the mesh independent study of the system using a platform's angle $=4^{\circ}$ and a launching speed of $0.79 \mathrm{~m} / \mathrm{s}$.

Table 5. Mesh independent study

\begin{tabular}{ccc}
\hline Case & Total number of real cell & Tipping Time, $(\mathrm{s})$ \\
\hline A & $2,045,832$ & 1.115 \\
B & $3,366,492$ & 1.109 \\
C & $5,005,347$ & 1.102 \\
D & $6,494,044$ & 1.113 \\
\hline
\end{tabular}

\section{RESULTS AND DISCUSSION}

A series of ship launches was successfully conducted using the CFD simulation approach based on the aforementioned parametric studies. The computational simulation results are appropriately presented; meanwhile, the effect of the platform's angle magnitude and the length of the launching/sliding platform depending on the tipping time characteristics are discussed.

\section{Effect of Platform's Angle}

The effect of the platform's angle on the ship's side launching performance is displayed in Figure 4. Correspondingly, the launching speed, rolling motion, UKC, water splash and heaving motions of the ship are discussed as follows. The increase in platform angle was proportional with the increase of the launching speed, and inversely proportional with the decrease in tipping time. The computational simulations showed that the use of a smaller platform angle at $3^{\circ}$ resulted in less launching speed at about $0.67 \mathrm{~m} / \mathrm{s}$ in which the tipping time was increased by $1.40 \mathrm{~s}$. A larger platform angle, $5^{\circ}$ produced a faster tipping time of $0.90 \mathrm{~s}$. This can be explained by the fact that the launching speed had sufficiently increased by $0.86 \mathrm{~m} / \mathrm{s}$. Referring to Table 6 , the subsequent increase of the platform's angle from $3^{\circ}$ to $4^{\circ}$ and from $4^{\circ}$ to $5^{\circ}$ had led to increases in the percentage of 
the launching speed by $17.9 \%$ and $8.1 \%$, respectively. Correspondingly, the percentage of tipping time had become faster by about $21.4 \%$ and $18.1 \%$, respectively. In the case of the ship entering into the pool/water, the ship would inherently float, leading towards her equilibrium condition. This is reasonable since the ship has a natural damping motion with respect to her lateral and rotational motions. It should be noted here that the rolling motion is considered as the most critical motion in a ship's side launching as there are large concentrated forces imparted on the ship's sections due to pivoting pressure [14]. The lowest rolling motion response had occurred in the simulation using the $4^{\circ}$ platform angle. This aforementioned platform angle had resulted in a higher level of safety of the ship's side launching as compared to $3^{\circ}$ and $5^{\circ}$.
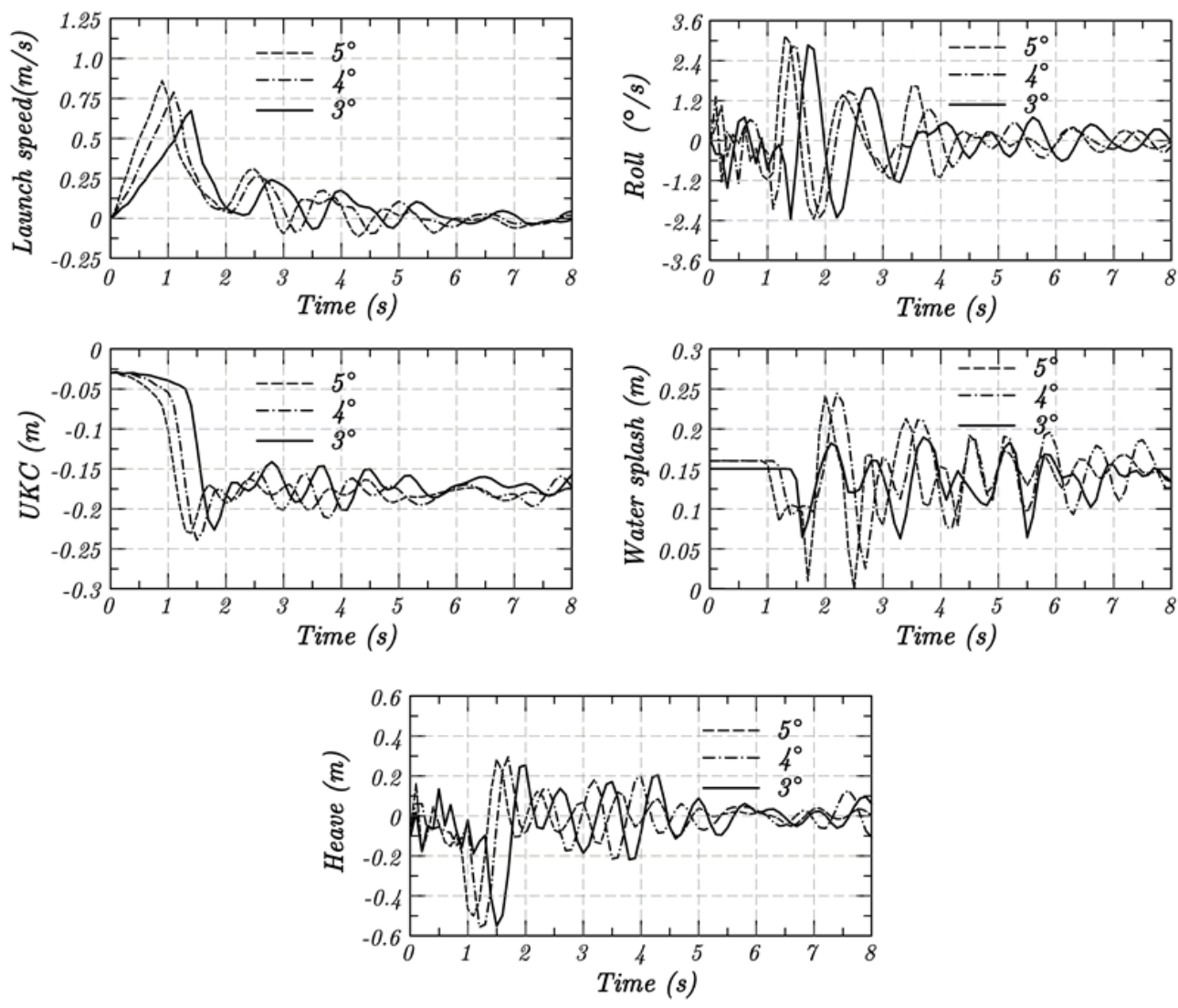

Figure 4. Characteristics of ship's launching performance at various platform angles

Table 6. Tipping times at various platform angles

\begin{tabular}{ccc}
\hline Platform angle,$\left(^{\circ}\right)$ & Launching Speed, $(\mathrm{m} / \mathrm{s})$ & Tipping Time, $(\mathrm{s})$ \\
\hline 3 & 0.67 & 1.4 \\
4 & 0.79 & 1.10 \\
5 & 0.86 & 0.9 \\
\hline
\end{tabular}

However, the effect of the platform's angle was insignificant to influence her heave motion behaviour as seen in Figure 4. Based on the probes located on the surface of the water, the increase of the platform's angle had resulted in a proportional increase in the water splashing's elevation. Furthermore, UKC behaviour was varied with respect to the magnitude of the platform's angle. In the simulations using the $3^{\circ}$ and $4^{\circ}$ platform angles, 
the maximum UKC were $0.23 \mathrm{~m}$ and $0.22 \mathrm{~m}$, respectively, in which it was measured from the seabed of the pool. This means that the increase of the platform's angle had caused the ship to fall down into less UKC. This is mainly due to the fact that the increments in the platform's angle had increased the speed of launching.
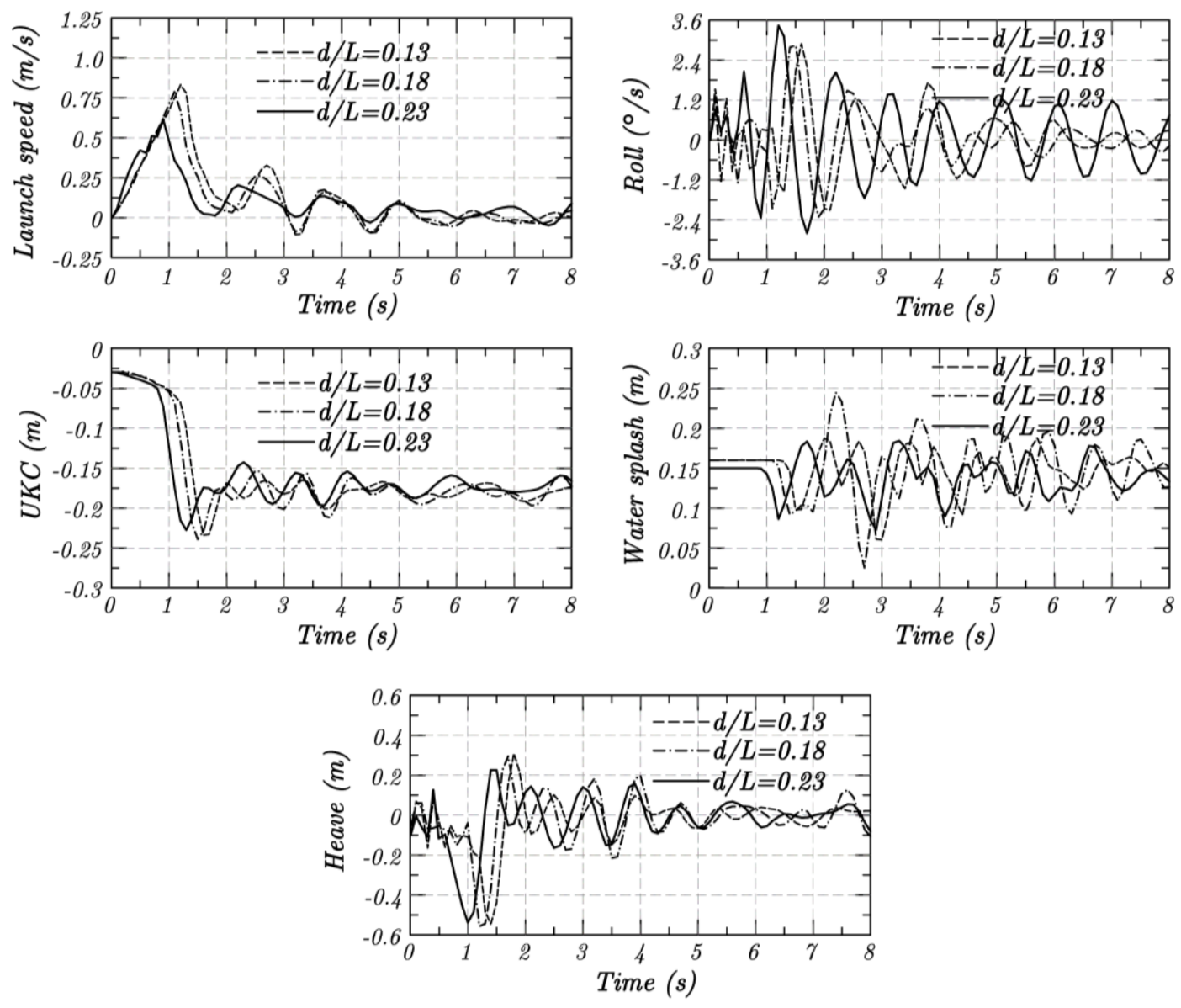

Figure 5. Characteristics of ship launching performance at various platform distances.

\section{Effect of Platform's Distance}

Figure 5 shows the characteristics of the ship's side launching performance due to effect of the various lengths of the launching's platform. The behaviour of the launching speed, her rolling and heave motions, UKC and the water splashing characteristics once the ship falling into the pool/water are properly discussed below. Referring to Table 7, the subsequent increase in $\mathrm{d} / \mathrm{L}$ ratio is proportional to the increase in the launching speed. Based on the computational analysis, the launching speed had increased by $27.2 \%$ and $5.1 \%$ as the $\mathrm{d} / \mathrm{L}$ ratio was increased from 0.13 to 0.18 and 0.18 to 0.23 , respectively. However, the results also showed that the tipping time had become slower. This is justifiable because when the launching distance (d) is increased, it substantially contributes to lowering the tipping time. It should be noted that the increase of $d / L$ ratios is prone to increase the probability of the launched ship hitting the bottom/seabed of the pool. The possible reason for this might rest with the increase of $d / L$ ratio that cause the proportionally of the launched ship's acceleration before falling into the water. In this study, a d/L ratio of 0.18 was selected where the value of under keel clearance (UKC) was $0.22 \mathrm{~m}$. The magnitude of the rolling motion was significantly reduced as compared 
to using the $\mathrm{d} / \mathrm{L}$ ratios of 0.13 and 0.23 . This condition had directly led to a safer ship launching. As seen in the figure, the water splash graph shows that the wave elevation had varied for different platform distances. The increase of $d / L$ ratios have decreased the water splashing elevation. Here, the maximum water elevation was reduced as the $d / L$ ratio was increased from 0.13 up to 0.23 . Typically, the increase of $d / L$ ratios resulted in having almost a negligible effect on the ship's launching performance.

Table 7. Tipping time for various platform distances.

\begin{tabular}{ccc}
\hline Distance/Ship's Length, $(\mathrm{d} / \mathrm{L})(\mathrm{m})$ & Launching Speed, $(\mathrm{m} / \mathrm{s})$ & Tipping Time, $(\mathrm{s})$ \\
\hline 0.13 & 0.62 & 0.9 \\
0.18 & 0.79 & 1.1 \\
0.23 & 0.83 & 1.2 \\
\hline
\end{tabular}

Referring to Figure 6, the computational fluid dynamic simulation of the ship's side launching was clearly visualised to provide a better understanding of the ship's launching process/stages. As seen in Figure 6(a), the launching process has not commenced yet, and the ship remained in an upright position on the platform. The ship was then launched along the sliding platform towards the pool as displayed in Figure 6(b). It can be seen in Figure 6(c) that the ship's tipping time was then measured once the ship was positioned at the edge of the platform before she fell into the water/pool. In the situation where the launched ship has fully fallen into the pool, this ship would be freely floating (see Figure 6(d)) and dynamically moving into the six degrees of freedom as shown in Figure 6(e). Inherently, the launched ship would return to the upright position after experiencing unequilibrium conditions caused predominantly by her initial stiff rolling motions (Figure 6(f)).

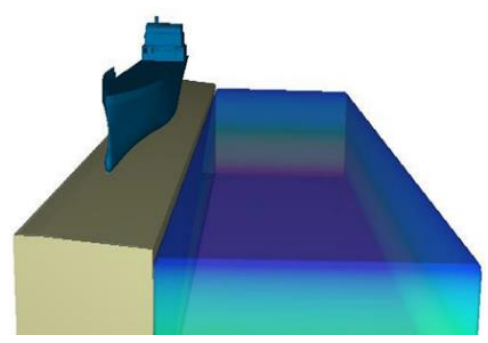

(a)

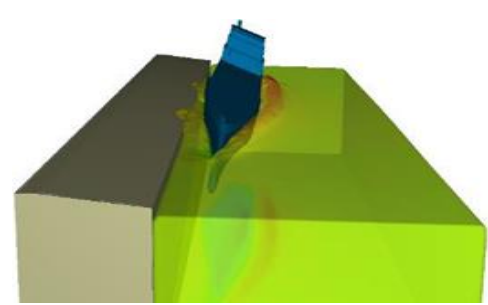

(d)

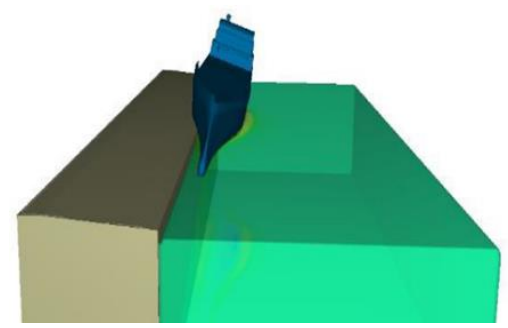

(b)

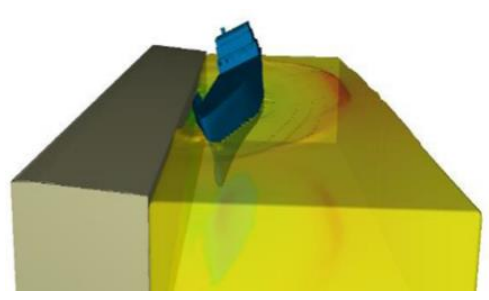

(e)

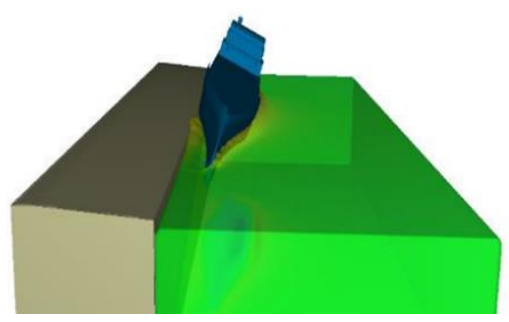

(c)

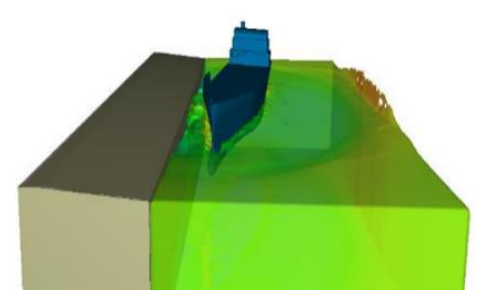

(f)

Figure 6. Visualization of a side launching simulation at $4^{\circ}$ and a ratio of $d / L=0.18$;

(a) initial ship position; (b) position of ship before tipping; (c) ship at tipping position;

(d) ship enters the water completely; (e) ship's dynamic motion into six-degrees-offreedom;(f) ship recovers into its equilibrium condition. 


\section{CONCLUSIONS}

A simulation of a ship's side launching has been successfully conducted using the computation fluid dynamic approach (CFD). Several parameters such as platform angle and ratio of the length of sliding platform with respect to ship's length $(\mathrm{d} / \mathrm{L})$ on the ship's side launching performance have been taken into account. The computational results are drawn as follows:

- Regardless of the various platform angles $\left(3^{\circ}, 4^{\circ}\right.$ and $\left.5^{\circ}\right)$, the subsequent increase of platform angles is proportional with the increase of the launching speed, which led to a faster tipping time by $21.4 \%$ as the platform angle was increased from $3^{\circ}$ to $4^{\circ}$.

- Inversely, the simulation results showed that the tipping time have become slower by $22.2 \%$ and $9.1 \%$ as the $\mathrm{d} / \mathrm{L}$ ratio was increased from 0.13 to 0.18 and from 0.18 to 0.23 , respectively.

- The effect of the various platform angles and the lengths of the launching platform are negligible to the ship's heave motion once the ship has fallen down into the pool.

It is generally concluded that increasing the platform's angle and decreasing the $\mathrm{d} / \mathrm{L}$ ratio result in a faster tipping time. With regards to the CFD results, these preliminary findings can act as best practice guidelines, especially for naval architect engineers.

\section{ACKNOWLEDGEMENTS}

The authors wish to greatly thank for the special financial support from School of Ocean Engineering, Universiti Malaysia Terengganu.

\section{REFERENCES}

[1] Ozkok M, Cebi S. A fuzzy based assessment method for comparison of ship launching methods. Journal of Intelligent \& Fuzzy Systems. 2014;26:781-91.

[2] Rudan S, Urem J, Zaninović A. Comparison of ship launching evaluation methods. XX Symposium on Theory and Practice in Shipbuilding SORTA 2012. 2012.

[3] Kraskowski M. Simplified RANSE simulation of a side launching. Archives of Civil and Mechanical Engineering. 2007;7:151-9.

[4] Nowacki H, Valleriani M, Max-Planck-Institut fuer Wissenschaftsgeschichte B. Shipbuilding practice and ship design methods from the Renaissance to the 18th century-a workshop report. 2003.

[5] Ye Z. Dynamics of ships side launching. Computers \& Structures. 1994;53:8615.

[6] Hak B. Numerical simulation of the side launching of a ship: University of Groningen; 2005.

[7] Qingdao. Qingdao Evergreen Shipping Supplies Co., Ltd. 2009.

[8] Flow3D 10.1.1 User Manual: Flow Science Inc.; 2013.

[9] Koutsourakis N, Bartzis JG, Markatos NC. Evaluation of Reynolds stress, k- $\varepsilon$ and RNG k- $\varepsilon$ turbulence models in street canyon flows using various experimental datasets. Environmental Fluid Mechanics. 2012:1-25.

[10] Yakhot A, Rakib S, Flannery W. Low-Reynolds number approximation for turbulent eddy viscosity. Journal of Scientific Computing. 1994;9:283-92. 
[11] Yakhot V, Orszag SA. Renormalization group analysis of turbulence. I. Basic theory. Journal of Scientific Computing. 1986;1:3-51.

[12] Saad I, Bari S. CFD investigation of in-cylinder air flow to optimize number of guide vanes to improve ci engine performance using higher viscous fuel. International Journal of Automotive and Mechanical Engineering. 2013;8:1096107.

[13] Lam S, Shuaib N, Hasini H, Shuaib N. Computational Fluid Dynamics Investigation on the Use of Heat Shields for Thermal Management in a Car Underhood. International Journal of Automotive and Mechanical Engineering. 2012;6:785-96.

[14] Volenyuk L, Rashkovskyi A. Ship stability analysis during launching from longitudinal sloping slipway by pneumatic airbags. International Shipbuilding Progress. 2017:1-10.

\section{NOMENCLATURE}

CFD Computational Fluid Dynamics

$\mathrm{d} / \mathrm{L} \quad$ Length of sliding platform with respect to the ship's length

DOF Degree of Freedom

F Force

GMO General Moving Object

$\mathrm{T} \quad$ Draft of ship

UKC Under Keel Clearance

VOF Volume of Fluid

WSA Wetted Surface Area of ship 